\title{
Synthesis and Characterization of Transition Metal Complexes with Benzimidazolyl-2-hydrazones of o-anisaldehyde and Furfural
}

\author{
R. K. Mohapatra*, U. K. Mishra ${ }^{\dagger}$, S. K. Mishra ${ }^{\dagger}$, A. Mahapatra ${ }^{\dagger}$, and D. C. Dash ${ }^{\dagger}$ \\ Department of Chemistry, Orissa School of Mining Engineering (Degree Stream), Keonjhar-758002, \\ Orissa, India. *E-mail: ranjank_mohapatra@yahoo.com \\ ${ }^{\dagger}$ School of Chemistry, Sambalpur University, Jyoti Vihar, Burla, Sambalpur-768019, Orissa, India
}

(Received July 13, 2011; Accepted November 4, 2011)

\begin{abstract}
A series of complexes of the type $\left[\mathrm{ML}_{2} \mathrm{Cl}_{2}\right]$, where $\mathrm{L}=2$-(o-anisylidene-2'-imino) amino benzimidazole (AIAB) and 2-(furfurylidene imino) amino benzimidazole (FIAB), $\mathrm{M}=\mathrm{Cu}(\mathrm{II}), \mathrm{Co}(\mathrm{II}), \mathrm{Ni}(\mathrm{II})$ and $\mathrm{Zn}(\mathrm{II})$, have been synthesized and characterized on the basis of elemental analysis, thermal analysis, molar conductivity, magnetic moment, electronic, infrared, ${ }^{1}$ H-NMR spectral studies. The results are in consistent with bidentate chelation of ligand with azomethine nitrogen and ring nitrogen donors. All these Schiff bases and their complexes have also been screened for their antibacterial (Bacillus subtilis, Bacillus stearothermophilus, Escherichia coli and Salmonella typhi) and antifungal activities (Aspergillus niger and Aspergillus flavus).
\end{abstract}

Key words: Benzimidazolyl-2-hydrazones, o-anisaldehyde, Furfural and Transition metal complexes

\section{INTRODUCTION}

Schiff base complexes have undergone a phenomenal growth during the recent years because of the versatility offered by these complexes in the field of industries, ${ }^{1,2}$ catalysis $^{3}$ and in biological system ${ }^{4,5}$ etc. In this way, the synthesis, structural investigation and reaction of transition metal Schiff bases have received a special attention, because of their biological activities as antitumoral, antifungal and antiviral activities. ${ }^{6}$ Thus, Schiff base hydrazones are also interesting from the point of view of pharmacology. Hydrazone derivatives are found to possess antimicrobial, ${ }^{7}$ antitubercular, ${ }^{8}$ anticonvulsant ${ }^{9}$ and antiinflammatory ${ }^{10}$ activities. Particularly, the antibacterial and antifungal properties of hydrazones and their complexes with some transition metal ions was studied and reported by Carcelli et al.. ${ }^{11}$ In addition, complexes of salicylaldehide benzoylhydrazone were shown to be a potent inhibitor of DNA synthesis and cell growth. ${ }^{12}$ This hydrazone also has mild bacteriostatic activity and a range of analogues has been investigated as potential oral ion chelating drugs for genetic disorders such as thalasemia. ${ }^{13,14}$

Following all these observations and as a part of our continuing research on the coordination chemistry of multidentate ligands, ${ }^{15-22}$ we report here the synthesis and structural studies on the complexes of $\mathrm{Cu}(\mathrm{II}), \mathrm{Co}(\mathrm{II}), \mathrm{Ni}(\mathrm{II})$ and $\mathrm{Zn}$ (II) with some hydrazone derivatives containing benzimidazole moiety such as 2-(o-anisylidene-2'-imino) amino benzimidazole (AIAB) and 2-(furfurylidene imino) amino benzimidazole (FIAB).

\section{EXPERIMENTAL}

\section{Materials and Methods}

All the chemicals used of AR grade. The solvents were purified before use by standard procedures. The starting material such as 2-hydrazinobenzimidazole was synthesized according to literature method. ${ }^{23}$

\section{Preparation of Ligands}

The ligands used in the present investigation were benzimidazolyl-2-hydrazones of aldehydes and ketones such as o-anisaldehyde and furfural have been synthesized by condensing 2-hydrazinobenzimidazole with respective aldehydes and ketone in the following manner.

Ethanolic solution of 2-hydrazinobenzimidazole (0.01 mol in $20 \mathrm{~mL}$ ) was added to ethanolic solution of o-anisaldehyde/furfural $(0.01$ mole in $20 \mathrm{~mL})$, followed by addition of 2 to 3 drops of piperidine as condensing agent, to the above mixture. The resulting solution was refluxed on a water bath for 3 hours. It was concentrated and allowed to stand overnight when coloured precipitate was separated out in each case. It was filtered, washed and recrystallised from ethanol. The sample was dried in vacuo over fused calcium chloride and then analysed. 


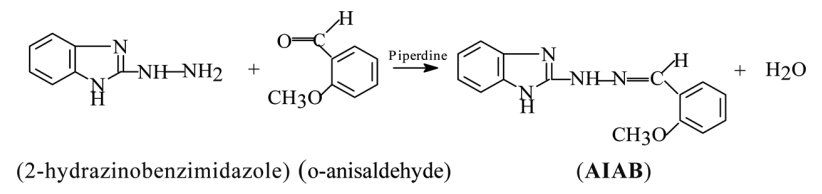

Scheme 1.

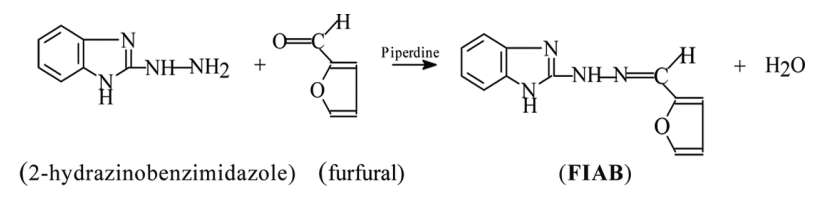

Scheme 2.

\section{Preparation of the complexes}

A hot ethanolic solution of the ligand AIAB/FIAB $(0.02$ mole in $20 \mathrm{~mL}$ ) was treated with ethanolic solution of respective hydrated metal (II) chloride ( 0.01 mole in 20 $\mathrm{mL}$ ) and the reaction mixture was refluxed on a water bath with constant stirring for about 2-3 hours. The resulting liquid was filtered and allowed to cool when coloured crystals of the corresponding metal complexes separated out in each case. The complexes were filtered, washed with ethanol followed by ether and finally dried in vacuo over fused $\mathrm{CaCl}_{2}$.

Analysis and Physical measurements: A weighed quantity of the compound (0.2-0.3 g) was treated with a few drops of concentrated $\mathrm{H}_{2} \mathrm{SO}_{4}$ and $1 \mathrm{cc}$. of concentrated $\mathrm{HNO}_{3}$. It was heated till all the organic matter decomposed and sulphur trioxide fumes came out. The same process was repeated two to three times to decompose the substance completely. Then it was dissolved in water and the resulting solution was used for analysis of metal ions. The metal contents in the complexes were determined gravimetrically following standard procedure. ${ }^{24}$ Sulphur was determined as $\mathrm{BaSO}_{4}$. The molar conductance measurements were carried out at room temperature with a
Toshniwal conductivity Bridge (model CL-01-06, cell constant $0.5 \mathrm{~cm}^{-1}$ ) using $1 \times 10^{-3} \mathrm{M}$ solution of the complexes in DMSO. Carbon, hydrogen and nitrogen contents of the complexes were determined by using a MLW$\mathrm{CHN}$ micro analyser. FTIR spectra in $\mathrm{KBr}$ pallets were recorded on a Varian FTIR spectrophotometer, Australia. The electronic spectra of the complexes in DMSO were recorded on a Perkin-Elmer spectrophotometer. Thermo gravimetric analysis was done by Netzch-429 thermo analyzer. The ${ }^{1} \mathrm{H}-\mathrm{NMR}$ spectra of the complexes were recorded in DMSO- $\mathrm{d}_{6}$ medium on JEOL, GSX-400 model equipment.

\section{RESULTS AND DISCUSSION}

The complexes were formulated from the analytical data and molar conductance data support the suggested formulae (Table 1). The complexes are highly coloured and insoluble in water and common organic solvents but soluble in highly coordinating solvents such as dioxane, DMF and DMSO. They are non hygroscopic, highly stable under normal conditions and all of them decompose above $250{ }^{\circ} \mathrm{C}$. The molar conductance data values in DMSO for the complexes indicate them to be non-electrolyte in nature.

\section{IR spectra}

The IR spectra of the ligands AIAB and FIAB and their metal complexes have been studied in concert for the appraisal of the structure of the complexes. The formation of the above ligands via the condensation of each of oanisaldehyde/furfural with 2-hydrazinobenzimidazole has been confirmed by the disappearance of band due to $v_{\mathrm{NH} 2}$ and appearance of a new band at $\sim 1600 \mathrm{~cm}^{-1}$ which undoubtedly originates due to newly introduced azome-

Table 1. Analytical and physical data of the ligands and their complexes

\begin{tabular}{cccccccccc}
\hline Sl no & Compounds & Colours & $\begin{array}{c}\text { Yields } \\
(\%)\end{array}$ & $\Lambda_{\mathrm{m}}^{\mathrm{a}}$ & $\begin{array}{c}\text { C Found } \\
(\text { Calcd })\end{array}$ & $\begin{array}{c}\text { H Found } \\
(\text { Calcd })\end{array}$ & $\begin{array}{c}\text { N Found } \\
(\text { Calcd })\end{array}$ & $\begin{array}{c}\text { Cl Found } \\
(\text { Calcd })\end{array}$ & $\begin{array}{c}\text { M Found } \\
(\text { Calcd })\end{array}$ \\
\hline 1 & $\mathrm{AIAB}$ & Light yellow & 80 & - & $40.78(40.82)$ & $5.23(5.26)$ & $44.41(44.44)$ & - & - \\
2 & $\mathrm{FIAB}$ & Light brown & 83 & - & $41.23(41.26)$ & $4.38(4.42)$ & $40.06(40.11)$ & - & - \\
3 & $\mathrm{Co}(\mathrm{AIAB})_{2} \mathrm{Cl}_{2}$ & Silver grey & 65 & 23.10 & $54.34(54.38)$ & $2.08(2.11)$ & $16.89(16.92)$ & $10.68(10.72)$ & $8.88(8.91)$ \\
4 & $\mathrm{Ni}(\mathrm{AIAB})_{2} \mathrm{Cl}_{2}$ & Royal ivory & 62 & 21.35 & $54.39(54.41)$ & $2.09(2.11)$ & $16.90(16.93)$ & $10.70(10.73)$ & $8.80(8.84)$ \\
5 & $\mathrm{Cu}(\mathrm{AIAB})_{2} \mathrm{Cl}_{2}$ & Cannery yellow & 63 & 21.90 & $53.98(54.01)$ & $2.07(2.10)$ & $16.76(16.80)$ & $10.61(10.65)$ & $9.48(9.53)$ \\
6 & $\mathrm{Zn}(\mathrm{AIAB})_{2} \mathrm{Cl}_{2}$ & White & 64 & 22.12 & $53.81(53.86)$ & $2.05(2.09)$ & $16.74(16.76)$ & $10.59(10.62)$ & $9.69(9.73)$ \\
7 & $\mathrm{Co}(\mathrm{FIAB})_{2} \mathrm{Cl}_{2}$ & Brown & 60 & 18.35 & $49.44(49.48)$ & $1.69(1.72)$ & $19.21(19.24)$ & $12.15(12.19)$ & $10.11(10.13)$ \\
8 & $\mathrm{Ni}(\mathrm{FIAB})_{2} \mathrm{Cl}_{2}$ & Pale green & 61 & 23.68 & $49.48(49.51)$ & $1.70(1.72)$ & $19.22(19.25)$ & $12.18(12.20)$ & $10.02(10.06)$ \\
9 & $\mathrm{Cu}(\mathrm{FIAB})_{2} \mathrm{Cl}_{2}$ & Steel grey & 63 & 21.65 & $49.08(49.10)$ & $1.68(1.71)$ & $19.05(19.09)$ & $12.06(12.10)$ & $10.79(10.82)$ \\
10 & $\mathrm{Zn}(\mathrm{FIAB})_{2} \mathrm{Cl}_{2}$ & White & 60 & 20.25 & $48.91(48.95)$ & $1.64(1.70)$ & $19.01(19.04)$ & $12.04(12.07)$ & $11.01(11.05)$ \\
\hline $\mathrm{Ohm}^{-1} \mathrm{~cm}^{2} \mathrm{~mole}^{-1}$ & & & & & & & & &
\end{tabular}


thine $(\mathrm{C}=\mathrm{N})$ group. The presence of furan ring in FIAB and $-\mathrm{OCH}_{3}$ group in AIAB are also indicated by the appearance of bands at $\sim 1510$ and $\sim 2840 \mathrm{~cm}^{-1}$ in their respective spectrum assignable to $\mathrm{v}_{\mathrm{C}-\mathrm{O}-\mathrm{C}}$ of furan ring and $-\mathrm{O}-\mathrm{CH}_{3}$ group of o-anisaldehyde respectively. ${ }^{25}$ The position of above bands remain practically unaltered in the IR spectra of complexes there by suggesting non participation of furan ring oxygen and methoxy oxygen atom in coordination.

The characteristic IR bands observed in the spectra of the ligands at $\sim 1560, \sim 1303 \mathrm{~cm}^{-1}$ are assigned to $v_{\mathrm{C}=\mathrm{N}}$ (cyclic) $v_{\mathrm{C}-\mathrm{N}}$ (cyclic) of benzimidazole group respectively. Analogous to the previous complexes, the position of both the band remain unaltered suggesting there by nonparticipation of ring $\mathrm{N}$ atom $(-\mathrm{C}=\mathrm{N})$ in complexation. However, $v_{\mathrm{NH}}$ band of benzimidazole ring $(-\mathrm{N}-\mathrm{H})$ group was found invariably shifted $20-10 \mathrm{~cm}^{-1}$ towards negative side indicating the coordination of benzimidazole ring $\mathrm{NH}$ group to the metal ions. Where as band occurring at $\sim 3100 \mathrm{~cm}^{-1}$ due to $v_{\mathrm{N}-\mathrm{H}}$ exocyclic remains practically unaltered indicating it's non involvement either in coordination or enolisation. Besides the above, the bands occurring at $\sim 1600$ and $\sim 1010 \mathrm{~cm}^{-1}$ assignable to azomethine $\left(v_{\mathrm{C}=\mathrm{N}}\right)$ group and $\left(v_{\mathrm{N}-\mathrm{N}}\right)$ respectively shifted their position on complexasation. Like previous cases here also, $v_{\mathrm{C}=\mathrm{N}}$ band under goes red shift where as $v_{\mathrm{CN}}$ band shows blue shift indicating coordination of azomethine nitrogen atom to metal ions. This is further confirmed by the presence of a band at $\sim 525 \mathrm{~cm}^{-1}$ due to $v_{\mathrm{NN}}$. It is interesting to note that presence of electron releasing group like $-\mathrm{OCH}_{3}$ and -C-O-C- near the condensation site only enhance conjugation but do not take part in coordination most probably due to steric hindrance.

Although evidence of $v_{\mathrm{M}-\mathrm{Cl}}$ band could not be brought in the present investigation due to instrumental limitation, the insolubility of the complexes in water and their nonelectrolytic nature provide sufficient evidence for the coordination of the counter ions $\mathrm{Cl}^{-}$to form neutral complexes.

\section{Thermal analysis}

Thermal characteristics of the complexes formed by AIAB and FIAB are recorded in Table 2. These complexes follow the same pattern of thermal decomposition. An examination of thermograms of the complexes reveals that, the complexes remain almost stable up to $\sim 235^{\circ} \mathrm{C}$ indicating absence of water molecules. Beyond this range, the complexes decompose rapidly leaving their stable residues. The rapid decomposition denotes loss of ligand moiety. It has been observed that the composition of the residue corresponds to the respective metal oxides. The decomposition temperature varies for different complexes. The representative thermogram of $\mathrm{Cu}(\mathrm{AIAB})_{2} \mathrm{Cl}_{2}$ complex is shown in Fig. 1. Thermal stability of the complexes is found to be in the following order:

$$
\begin{aligned}
& \text { AIAB Complexes: } \mathrm{Co}(\text { II })<\mathrm{Zn}(\text { II })<\mathrm{Cu}(\text { II })<\mathrm{Ni} \text { (II) } \\
& \text { FIAB Complexes: } \mathrm{Co}(\text { II })<\mathrm{Ni}(\text { II })<\mathrm{Cu}(\text { II })<\mathrm{Zn} \text { (II) }
\end{aligned}
$$

\section{Electronic spectra and magnetic properties}

The electronic spectral data and room temperature effective magnetic moment values of Co(II) complexes

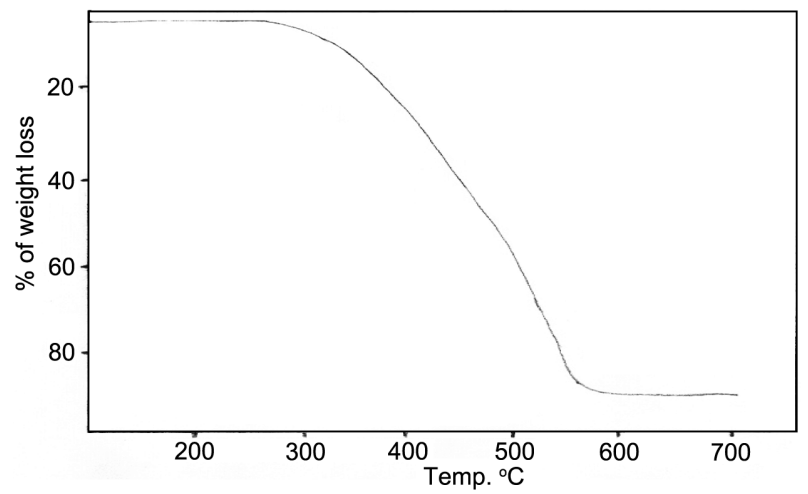

Fig. 1. Thermogram of $\mathrm{Cu}(\mathrm{AIAB})_{2} \mathrm{Cl}_{2}$.

Table 2. Important features of thermo gravimetric analysis (TGA)

\begin{tabular}{cccccc}
\hline $\begin{array}{c}\text { Sl. } \\
\text { no. }\end{array}$ & Compounds & $\begin{array}{c}\text { Total wt. of } \\
\text { TG }(\mathrm{mg})\end{array}$ & $\begin{array}{c}\text { Decomposition } \\
\text { temperature }\left({ }^{\circ} \mathrm{C}\right)\end{array}$ & $\begin{array}{c}\text { \% weight of residue } \\
\text { Found (calcd.) }\end{array}$ & $\begin{array}{c}\text { Composition of the } \\
\text { residue }\end{array}$ \\
\hline 1 & $\mathrm{Co}(\mathrm{AIAB})_{2} \mathrm{Cl}_{2}$ & 19.2 & $237-560$ & $11.29(11.33)$ & $\mathrm{CoO}$ \\
2 & $\mathrm{Ni}(\mathrm{AIAB})_{2} \mathrm{Cl}_{2}$ & 21.2 & $258-555$ & $11.23(11.26)$ & $\mathrm{NiO}$ \\
3 & $\mathrm{Cu}(\mathrm{AIAB})_{2} \mathrm{Cl}_{2}$ & 17.5 & $247-540$ & $11.91(11.93)$ & $\mathrm{CuO}$ \\
4 & $\mathrm{Zn}(\mathrm{AIAB})_{2} \mathrm{Cl}_{2}$ & 15.8 & $240-550$ & $12.08(12.12)$ & $\mathrm{ZnO}$ \\
5 & $\mathrm{Co}(\mathrm{FIAB})_{2} \mathrm{Cl}_{2}$ & 22.3 & $236-570$ & $12.84(12.88)$ & $\mathrm{CoO}$ \\
6 & $\mathrm{Ni}(\mathrm{FIAB})_{2} \mathrm{Cl}_{2}$ & 21.7 & $240-570$ & $12.78(12.81)$ & $\mathrm{NiO}$ \\
7 & $\mathrm{Cu}(\mathrm{FIAB})_{2} \mathrm{Cl}_{2}$ & 20.1 & $252-575$ & $13.52(13.55)$ & $\mathrm{CuO}$ \\
8 & $\mathrm{Zn}(\mathrm{FIAB})_{2} \mathrm{Cl}_{2}$ & 16.4 & $260-585$ & $13.75(13.77)$ & $\mathrm{ZnO}$ \\
\hline
\end{tabular}


with the ligands AIAB and FIAB are recorded. The room temperature $\mu_{\text {eff }}$ value of these complexes lies in the range 4.40-4.63 B.M. i.e., lower than expected for high spin pesudo-octahedral Co(II) species. ${ }^{26}$ This lower $\mu_{\text {eff }}$ value may be due to distorted structure of $\mathrm{Co}$ (II) complexes under $\mathrm{C}_{2}$ symmetry. As in $\mathrm{C}_{2}$ symmetry the degeneracy of the ground state of the metal ion will be lifted and the new ground state being an orbital singlet state will give rise to much lower magnetic moment than expected. ${ }^{27}$ Thus one can infer that the present $\mathrm{Co}$ (II) complexes probably have an orbital singlet ground state with distorted octahedral environment, which is further evidenced by electronic spectral data.

The electronic spectra of these complexes show a broad band at $\sim 9000 \mathrm{~cm}^{-1}(1111 \mathrm{~nm})$ and a split band at $\sim 19,200$ $20,500 \mathrm{~cm}^{-1}(520-487 \mathrm{~nm})$. The former band is attributed to ${ }^{4} \mathrm{~T}_{1 \mathrm{~g}}(\mathrm{~F}) \rightarrow{ }^{4} \mathrm{~T}_{2 \mathrm{~g}}(\mathrm{~F})\left(v_{1}\right)$ and the later one is due to ${ }^{4} \mathrm{~T}_{1 \mathrm{~g}}(\mathrm{~F})$ $\rightarrow{ }^{4} \mathrm{~T}_{1 \mathrm{~g}}(\mathrm{P})\left(v_{3}\right)$ transitions respectively under $\mathrm{O}_{\mathrm{h}}$ geometry. The broad asymmetrical curve seen as $v_{1}$ suggests the presence of other bands which are superimposed by the $v_{1}$ band. It is possible to calculate the values of $\mathrm{Dq}$ and $\mathrm{B}$ using band position of $v_{1}$ and $v_{3}$, following same method as in previous cases. Value of $v_{2}$ has been calculated to be around $\sim 19000 \mathrm{~cm}^{-1}(526 \mathrm{~nm})$. Thus, the observed weak shoulder near $\sim 19000 \mathrm{~cm}^{-1}$ may be tentatively assigned to $v_{2}$ transition. From this it is concluded that the band around $\sim 16000-16,500 \mathrm{~cm}^{-1}$ is most likely due to spin forbidden ${ }^{4} \mathrm{~T}_{1 \mathrm{~g}}(\mathrm{~F}) \rightarrow{ }^{2} \mathrm{~T}_{2 \mathrm{~g}}(\mathrm{G})$ transition and not due to ${ }^{4} \mathrm{~T}_{1 \mathrm{~g}}(\mathrm{~F})$ $\rightarrow{ }^{4} \mathrm{~A}_{2 \mathrm{~g}}(\mathrm{~F})\left(\mathrm{v}_{2}\right)$ transition.

The spectral characteristics of $\mathrm{Co}$ (II) complexes with AIAB and FIAB ligands with $\mathrm{Cl}^{-}$as co ligand do not indicate pure octahedral or $\mathrm{D}_{4 \mathrm{~h}}$ symmetry, rather it suggests approximately $\mathrm{C}_{2}$ geometry having distorted six coordinate as supported by $\mu_{\text {eff }}$ values. This however requires splitting of $v_{1}$ and $v_{3}$ bands due to lowering of symmetry. ${ }^{28}$ The electronic spectra has bands in the region $\sim 19,200$ $20,500 \mathrm{~cm}^{-1}$ which may be considered as the split component of $\nu_{3}$ band and the shoulder near $19,000 \mathrm{~cm}^{-1}$ might also contain one of the split Component of $v_{3}$ band. Although no split Component of $v$ band is observed, yet the presence of a broad envelope suggests superimposition of the different components into a single one.

The electronic spectral data and $\mu_{\text {eff }}$ value room temperature for $\mathrm{Ni}(\mathrm{II})$ complexes with ligands $\mathrm{AIAB}$ and FIAB with $\mathrm{Cl}^{-}$as co ligand have recorded. The observed $\mu_{\text {eff }}$ values for these complexes advocate for a tetragonal six-coordinated spin free Ni(II) species. ${ }^{29}$ The electronic spectra of the complexes show a number of bands in the range, $\sim 8,600 \mathrm{~cm}^{-1}(1160 \mathrm{~nm}), \sim 10,400 \mathrm{~cm}^{-1}(961 \mathrm{~nm})$, $\sim 14,000 \mathrm{~cm}^{-1}(714 \mathrm{~nm})$ and $\sim 26,000 \mathrm{~cm}^{-1}(386 \mathrm{~nm})$. These types of spectral features can be explained on the basis of energy level schemes derived by Ballhausen and coworkers ${ }^{30}$ for $\mathrm{D}_{4 \mathrm{~h}}$ symmetry. The first two bands correspond to the split components of ${ }^{3} \mathrm{~T}_{2 \mathrm{~g}}$ (F) namely; ${ }^{3} \mathrm{~B}_{1 \mathrm{~g}}$ $\rightarrow{ }^{3} \mathrm{E}_{\mathrm{g}}$ and ${ }^{3} \mathrm{~B}_{1 \mathrm{~g}} \rightarrow{ }^{3} \mathrm{~B}_{2 \mathrm{~g}}$ while the third and fourth are due to ${ }^{3} \mathrm{~B}_{1 \mathrm{~g}} \rightarrow{ }^{3} \mathrm{~A}_{2 \mathrm{~g}}$ and ${ }^{3} \mathrm{~B}_{1 \mathrm{~g}} \rightarrow{ }^{3} \mathrm{E}_{\mathrm{g}}$ the split components of ${ }^{3} \mathrm{~T}_{1 \mathrm{~g}}(\mathrm{~F})$ term. The fifth one can be assigned to ${ }^{3} \mathrm{~B}_{1 \mathrm{~g}}(\mathrm{P}) \rightarrow{ }^{3} \mathrm{~T}_{1 \mathrm{~g}}(\mathrm{P})$ transition. In this case the ground state term $\mathrm{A}_{2 \mathrm{~g}}$ under $\mathrm{O}_{\mathrm{h}}$ symmetry has been transformed to ${ }^{3} \mathrm{~B}_{2 \mathrm{~g}}$ term under $\mathrm{D}_{4 \mathrm{~h}}$ symmetry. ${ }^{31}$

The electronic spectral data and room temperature $\mu_{\text {eff }}$ values of $\mathrm{Cu}$ (II) complexes with ligands AIAB and FIAB are recorded. The $\mu_{\text {eff }}$ value in theses cases lie in the range 1.82-1.88 B.M. as expected for hexa coordinated spin free $\mathrm{Cu}(\mathrm{II})$ complexes in distorted octahedral environment. In the electronic spectra of these complexes one broad envelope is seen at $\sim 16,000 \mathrm{~cm}^{-1}(625 \mathrm{~nm})$. Suggesting superimposition of $v_{1}, v_{2}$ and $v_{3}$ transitions because of similar energy. Thus above band corresponds to ${ }^{2} \mathrm{E}_{\mathrm{g}} \rightarrow{ }^{2} \mathrm{~T}_{2 \mathrm{~g}}$ transition under a distorted octahedral environment. The width of the band provides evidence for distortion. The representative spectrum of the $\mathrm{Ni}(\mathrm{FIAB})_{2} \mathrm{Cl}_{2}$ complex is shown in Fig. 2.

\section{${ }^{1}$ H-NMR spectra}

In the ${ }^{1} \mathrm{H}$ NMR spectrum of the ligand AIAB, the multiplet is observed at $\delta 8.0-8.7 \mathrm{ppm}$ correspond to 4 aromatic protons of benzimidazolyl group and 4 aromatic protons $-\mathrm{C}_{6} \mathrm{H}_{4}\left(\mathrm{OCH}_{3}\right)$ group. A signal observed at $\delta 7.0$ ppm and $\delta 9.2$ ppm correspond to ring $\mathrm{NH}$ proton of benzimidazolyl group and exocyclic -NH-N= proton respectively. Besides the above peaks, a sharp signal at $\delta 9.4$ ppm and $\delta 4.7 \mathrm{ppm}$ observed due to azomethine (-N= $\mathrm{CH}-)$ protons and $\mathrm{O}_{-} \mathrm{CH}_{3}$ group respectively. In case of AIAB complexes, the NH (cyclic) proton of benzimidazolyl group show downfield shift indicating thereby

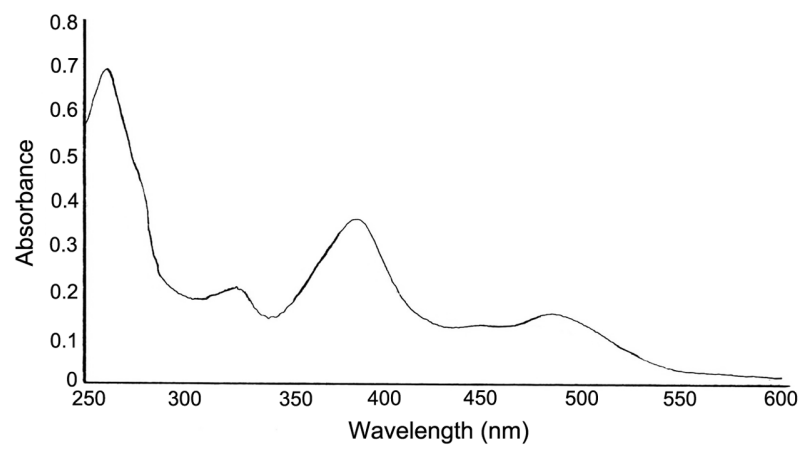

Fig. 2. Electronic spectra of $\mathrm{Ni}(\mathrm{FIAB})_{2} \mathrm{Cl}_{2}$. 


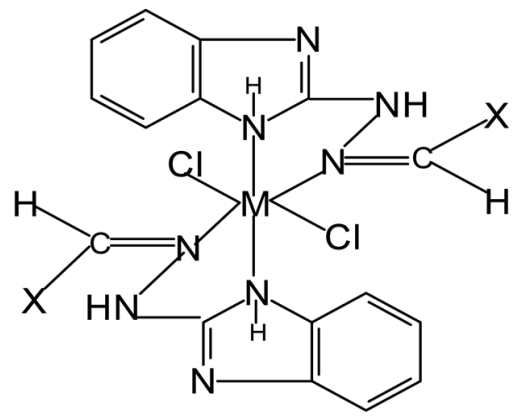

Fig. 3. $\mathrm{M}=\mathrm{Co}(\mathrm{II}), \mathrm{Ni}(\mathrm{II}), \mathrm{Cu}(\mathrm{II})$ and $\mathrm{Zn}(\mathrm{II})$.

the coordination of ring $\mathrm{NH}$ group to the metal ions, while the azomethine proton show upfield shift in the conformity with the coordination of azomethine group in complexes.

In the ${ }^{1} \mathrm{H}$ NMR spectrum of the ligand FIAB, the multiplet is observed at $\delta 8.0-8.7 \mathrm{ppm}$ correspond to 4 aromatic protons of benzimidazolyl group and 3 additional peaks at $\delta 5.4, \delta 6.3$ and $\delta 7.4$ ppm corresponding to $\mathrm{H}-3$, $\mathrm{H}-4$ and $\mathrm{H}-5$ of $\left(-\mathrm{C}_{4} \mathrm{H}_{3} \mathrm{O}\right)$ ring. A signal observed at $\delta 7.0$ ppm and $\delta 9.0 \mathrm{ppm}$ correspond to ring $\mathrm{NH}$ proton of benzimidazolyl group and exocyclic -NH-N= proton respectively. Besides the above peaks, a sharp signal at $\delta 9.4$ $\mathrm{ppm}$ is observed due to azomethine (-N=CH-) protons. In case of FIAB complexes, the NH (cyclic) proton of benzimidazolyl group show downfield shift indicating thereby the coordination of ring $\mathrm{NH}$ group to the metal ions, while the azomethine proton show upfield shift in the conformity with the coordination of azomethine group in complexes. It is to be noted that the multiplet due to aromatic proton undergoes downfield shift to some extent probably due to the involvement of ring $\mathrm{NH}$ group to the complexation because of lowering electron density in the ring system.

Based on the foregoing observations the following ten- tative structure (Fig. 3) has been proposed for the present complexes.

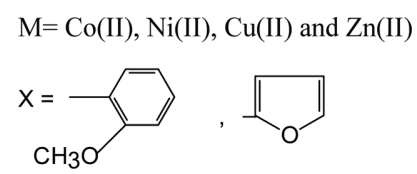

\section{Antibacterial and antifungal activity}

The Antibacterial activities of the synthesized complexes were evaluated by the Agar Well Diffusion Assay Technique against two Gram positive bacteria, i.e., Bacillus subtilis and Bacillus stearothermophilus and two Gram negative bacteria, i.e., Escherichia coli and Salmonella typhi. Solutions of the ligands and its complexes in DMF were plated onto the cultured agar medium and incubated for a period of $24 \mathrm{~h}$ at $37^{\circ} \mathrm{C}$. After the incubation period, the plates were observed for zones of inhibition (in $\mathrm{cm}$ ). The antifungal activities of the complexes were determined against two fungal strains, i.e., A. niger and A. flavus. The complexes showed good antibacterial and antifungal activities (Table 3) against the species. This may be explained on the basis that their structures mainly possess $\mathrm{C}=\mathrm{N}$ bonds. Moreover, coordination reduces the polarity ${ }^{27,32}$ of the metal ion mainly because of the partial sharing of its positive charge within the chelate ring formed during coordination. This process increases the lipophilic nature of the central metal atom, which favors its permeation more efficiently through the lipid layer of the micro-organism ${ }^{33-35}$ thus destroying them more aggressively. In addition to this, many other factors, such as solubility, dipole moment and conductivity, which are influenced by the metal ion may be the possible reasons for the antibacterial activities of these metal complexes. ${ }^{36}$

Table 3. Antibacterial and antifungal activities of the compounds (for a concentration of $100 \mu \mathrm{g} \mathrm{mL}^{-1}$ )

\begin{tabular}{ccccccc}
\hline Compound & B. subtilis & B. stearothermophilus & E. coli & S. typhi & A. niger & A. flavus \\
\hline AIAB & 17.38 & 15.63 & 18.43 & 20.11 & 12.53 & 11.49 \\
FIAB & 16.76 & 13.39 & 19.54 & 21.67 & 7.84 & 9.28 \\
$\mathrm{Co}(\mathrm{AIAB})_{2} \mathrm{Cl}_{2}$ & 41.53 & 36.64 & 43.61 & 46.82 & 37.54 & 34.32 \\
$\mathrm{Ni}(\mathrm{AIAB})_{2} \mathrm{Cl}_{2}$ & 22.39 & 25.78 & 29.42 & 27.28 & 28.81 & 31.73 \\
$\mathrm{Cu}(\mathrm{AIAB})_{2} \mathrm{Cl}_{2}$ & 19.91 & 21.45 & 26.65 & 24.45 & 21.34 & 23.62 \\
$\mathrm{Zn}(\mathrm{AIAB})_{2} \mathrm{Cl}_{2}$ & 20.42 & 19.37 & 21.63 & 28.21 & 16.26 & 17.47 \\
$\mathrm{Co}(\mathrm{FIAB})_{2} \mathrm{Cl}_{2}$ & 28.23 & 19.87 & 31.73 & 33.57 & 18.28 & 20.78 \\
$\mathrm{Ni}(\mathrm{FIAB})_{2} \mathrm{Cl}_{2}$ & 21.85 & 26.27 & 28.49 & 25.32 & 20.61 & 17.58 \\
$\mathrm{Cu}(\mathrm{FIAB})_{2} \mathrm{Cl}_{2}$ & 25.83 & 22.19 & 27.46 & 28.32 & 12.23 & 16.34 \\
$\mathrm{Zn}(\mathrm{FIAB})_{2} \mathrm{Cl}_{2}$ & 22.48 & 18.67 & 24.52 & 19.34 & 15.47 & 14.38 \\
\hline
\end{tabular}


Acknowledgement. The authors gratefully acknowledge the services rendered by Director, Regional Sophisticated Instrumentation Center, I.I.T., Madras, for recording the spectra.

\section{REFERENCES}

1. Katsuki, T. Coord. Chem. Rev. 1995, 140, 189.

2. Di Bella, S. Chem. Soc. Rev. 2001, 30, 355.

3. Cogan, D. A.; Liu, G. C.; Kim, K. J.; Backes, B. J.; Ellman, J. A. J. Am. Chem. Soc. 1998, 120, 8011.

4. Pandeya, S. N.; Sriram, D.; Nath, G.; De Clercq, E. Eur. J. Pharma. Soc. 1999, 9, 25.

5. Raper, E. S. Coord. Chem. Rev. 1996, 153, 199.

6. Sridhar, S. K.; Pandeya, S. N.; Stables, J. P.; Ramesh, A. Eur. J. Pharm. Sci. 2002, 16, 129.

7. Vicini, P.; Zani, F.; Cozzini, P.; Doytchinova, I. Eur. J. Med. Chem. 2002, 37, 553.

8. Kocyigit-Kaymakcioglu, B.; Rollas, S. Farmaco 2002, 57, 595.

9. Ragavendran, J. V.; Sriram, D.; Patel, S. K.; Reddy, I. V.; Bharathwajan, N.; Stables, J.; Yogeeswari, P. Eur. J. Med. Chem. 2007, 42, 146.

10. Rollas, S.; Gulerman, N.; Erdeniz, H. Farmaco 2002, 57, 171.

11. Carcelli, M.; Mazza, P.; Pelizi, C.; Zani, F. J. Inorg. Biochem. 1995, 57, 43.

12. Johnson, D. K.; Murphy, T. B.; Rose, N. J.; Goodwin, W. H.; Pickart, L. Inorg. Chim. Acta 1982, 67, 159.

13. Ranford, J. D.; Vittal, J. J.; Wang, Y. M. Inorg. Chem. 1998, 37, 1226.

14. Buss, J. L.; Greene, B. T.; Turner, J.; Torti, F. M.; Torti, S. V. Curr. Top. Med. Chem. 2004, 4, 1623.

15. Dash, D. C.; Mahapatra, A.; Pathjoshi, S. B.; Mishra, U. K.; Naik, S. K. J. Indian Chem. Soc. 2006, 83, 782.

16. Dash, D. C.; Mahapatra, A.; Jena, P.; Naik, S. K.; Mishra, U. K. J. Indian Chem. Soc. 2007, 84, 1092.
17. Dash, D. C.; Mahapatra, A.; Mohapatra, R. K.; Ghosh, S.; Naik, P. Indian J. Chem. 2008, 47A, 1009.

18. Dash, D. C.; Mohapatra, R. K.; Ghosh, S.; Naik, P. J. Korean Chem. Soc. 2008, 52(5), 468.

19. Dash, D. C.; Mohapatra, R. K.; Ghosh, S.; Naik, P. J. Indian Chem. Soc. 2009, 86, 121.

20. Mohapatra, R. K. J. Indian Chem. Soc. 2010, 87, 1251.

21. Mohapatra, R. K.; Dash, D. C. J. Korean Chem. Soc. 2010, 54(4), 395.

22. Dash, D. C.; Mahapatra, A.; Naik, P.; Mohapatra, R. K.; Naik, S. K. J. Korean Chem. Soc. 2011, 55(3), 412.

23. Katz, L. J. Am. Chem. Soc. 1951, 73, 4007.

24. Vogel, A. I. A text book of Quantitative Inorganic Analysis, 3rd ed.; Longman and ELBS: 1969.

25. Kalsi, P. S. Spectroscopy of Organic Compounds, New Age International limited; New Delhi, 1998; p 77.

26. Carlin, R. L. Transition Metal Chemistry; Marcel Dekker Inc.: New York, 1965.

27. Lever, A. B. P. Inorganic Electronic Spectroscopy; Elsevier Publication: New York, 1968.

28. Ali, M. A.; Livingstone, S. E. Coord. Chem. Rev. 1974, 13, 101.

29. Bustoup, O.; Jorgensen, C. K. Acta Chem. Scand. 1957, 11, 1223.

30. Sacconi, L. Trans. Metal Chem. 1968, 4, 199.

31. Ballhausen, C. J.; Liehr, A. D. J. Am. Chem. Soc. 1959, $81,538$.

32. Balhausen, C. J. An Introduction to Ligand Field; McGraw Hill: New York, 1962.

33. Chohan, Z. H.; Pervez, H.; Kausar, S.; Supuran, C. T. Synth. React. Inorg. Met.-Org. Chem. 2002, 3, 529.

34. Chohan, Z. H.; Pervez, H.; Rauf, A.; Supuran, C. T. MetalBased Drugs 2002, 8, 42.

35. Chohan, Z. H.; Scozzafava, A.; Supuran, C. T. J. Enzyme Inhib. Med. Chem. 2003, 18, 259.

36. Chohan, Z. H.; Hassan, M. U.; Khan, K. M.; Supuran, C. T. J. Enzyme Inhib. Med. Chem. 2005, 20, 181. 